TECHNO: JURNAL PENELITIAN

Jurnal homepage: http://ejournal.unkhair.ac.id/index.php/Techno

Volume 08 Nomor 01 Mei 2019 DOI: http://dx.doi.org/10.33387/tk.v8i1.951

\title{
PROFIL BUTA WARNA PADA MAHASISWA BARU TAHUN AJARAN 2018/2019 DI KLINIK PRATAMA UNIVERSITAS KHAIRUN
}

\author{
Wahyunita ${ }^{1}$ dan Liasari Armaijn' ${ }^{1}$ \\ Program Studi Pendidikan Dokter, Fakultas Kedokteran Universitas Khairun, Ternate \\ Coresponding Author: unyta.ilham@gmail.com \\ Manuscript recieved:19-01-2019 Revision Accepted: 01-05-2019
}

\begin{abstract}
Abstrak
Buta warna menjadi masalah kesehatan yang cukup memprihatinkan di berbagai negara, bahkan di negara maju sekalipun. Ketidaktahuan seseorang terhadap kelainan buta warna yang dideritanya dapat berakibat fatal terhadap kinerjanya dan merugikan komunitas lain yang berinteraksi dengannya. Penelitian ini bertujuan untuk mengetahui karakteristik penderita buta warna pada mahasiswa Universitas Khairun. Penilitian ini merupakan penelitian deskriptif. Sampel pada peneltian ini adalah seluruh mahasiswa baru tahun ajaran 2018/2019 Universitas Khairun Ternate. Penelitian dilakukan dengan menilai beberapa variabel, yaitu berdasarkan jenis kelamin, jenis buta warna, dan riwayat penyakit mata sebelumnya. Hasil penelitian menunjukkan bahwa dari 1021 orang sampel didapatkan 9 orang (0,8\%) menderita buta warna dan 1012 orang (99,2\%) tidak menderita buta warna.
\end{abstract}

Kata kunci: Buta warna, Klinik Pratama, Mahasiswa baru

\section{PENDAHULUAN}

Seiring pesatnya perkembangan dunia modern dan teknologi, persepsi terhadap warna menjadi isu yang penting. Hal ini dikarenakan banyaknya peralatan modern yang memerlukan pemahaman tentang warna. Teknologi yang menggunakan pemahaman warna menjadi perhatian setiap orang, khususnya bagi penderita buta warna. Namun pada kenyataannya masih banyak orang yang menganggap sepele masalah buta warna, bahkan masih banyak yang tidak menyadari jika sedang menderita kelainan tersebut.

Banyak orang tidak menyadari kalau dirinya mengalami buta warna. Hal ini disebabkan karena buta warna merupakan kelainan genetik (Ganong, 2003; Guyton \& Hall, 2011). Sebagian orang baru mngetahui jika dirinya menderita kelainan ini pada saat tes kesehatan masuk sekolah, masuk perguruan tinggi, atau pada saat melamar pekerjaan pada suatu instansi tertentu. Pada pemeriksaan buta warna penderita baru menyadari kalau dirinya menderita kelainan ini seperti dengan pemeriksaan Uji Ishihara, Uji Holmgren-Thomson dan Uji Farnsworth-Munsell (Ilyas, 2003).

Saat ini, bebas buta warna merupakan persyaratan mutlak untuk bisa diterima pada berbagai jurusan di perguruan tinggi, hampir sebagian besar jurusan eksakta yang berkaitan dengan warna dalam keseharian pekerjaanya seperti jurusan kedokteran, kedokteran gigi, 
keperawatan, pertanian, biologi, kimia, fisika, geografi, teknik elektro, teknik kimia, teknik komputer, teknik lingkungan, arsitektur, design interior, dan lainnya.

Ketidaktahuan seseorang terhadap kelainan buta warna yang dideritanya dapat berakibat fatal terhadap kinerjanya dan merugikan komunitas lain yang berinteraksi dengannya. Di samping itu, untuk meningkatkan pencapaian kompetensi, beberapa perusahaan baik nasional maupun yang bertaraf internasional telah menjadikan bebas buta warna sebagai salah satu syarat diterimanya lamaran kerja. Oleh karena itu, pengetahuan tetang keberadaan penderita buta warna merupakan hal yang sangat penting guna meningkatkan kapasitas pekerjaan yang berdasar kompetensi, minat, bakat dan dapat memenuhi tuntutan profesi.

Buta warna menjadi masalah kesehatan yang cukup memprihatinkan di berbagai negara, bahkan di negara maju sekalipun. Sebagian besar buta warna disebabkan oleh faktor genetik dan kelainan ini dapat menyerang semua umur dan jenis kelamin. Di Amerika Serikat sekitar $7 \%$ dari populasi laki-laki atau 21 juta laki-laki dan 0,4\% dari populasi perempuan tidak bisa membedakan warna merah dan hijau. Di Australia insiden pada laki-laki juga lebih tinggi daripada perempuan, sekitar $8 \%$ pada laki-laki dan hanya0,4\% pada perempuan. Menurut salah satu riset 5-8\% laki-laki dan 0,5\% perempuan dilahirkan buta warna. Dan 99\% penderita buta warna termasuk dischromacy protanopia dan deuteranopia.

Melihat berbagai hal yang dipaparkan di atas, maka dipandang perlu untuk melakukan penelitian mengenai prevalensi penderita buta warna di Perguruan Tinggi. Meskipun penelitian ini lebih banyak manfaatnya bila diuji sedini mungkin sebelum mahasiswa baru memilih jurusannya, namun diharapkan data yang akan diberikan dapat membantu untuk para Dekan atau Kepala program studi untuk dapat mempertimbangkan dan membebaskan calon mahasiswanya untuk memilih program studi non eksakta yang sesuai dengan kelainannya.

Penelitian ini bertujuan untuk mengetahui karakteristik penderita buta warna pada mahasiswa Universitas Khairun. Dalam hal ini, peneliti akan meneliti jumlah penderita buta warna secara keseluruhan, membandingkan antara jumlah perempuan dan laki-laki yang menderita kelainan buta warna, serta melihat jenis buta warna apa yang diderita oleh mahasiswa Universitas Khairun.

\section{METODE PENELITIAN}

Jenis penelitian yang akan dilaksanakan adalah penelitian deskriptif. Penelitian ini dilaksanakan di Klinik Pratama Universitas Khairun pada saat pemeriksaan kesehatan Mahasiswa Baru Tahun Ajaran 2018/2019 pada tanggal 18 Juli -16 Agustus 2018. Sampel yang diambil adalah semua mahasiswa baru tahun ajaran 2018/2019 di Universitas Khairun yang memenuhi kriteria inklusi dan ekslusi. Sampel berjumlah 1021 orang yaitu 437 orang laki-laki dan 584 perempuan. Data yang dikumpulkan berupa data primer melalui pemeriksaan langsung kepada mahasiswa baru tahun ajaran 2018/2019 Universitas Khairun. Setelah dilakukan pengumpulan data, dilakukan pengolahan data secara analisis. Data yang telah diolah, selanjutnya disusun dan disajikan dalam bentuk tabel menurut variabel sesuai tujuan disertai dengan penjelasan. 


\section{HASIL DAN PEMBAHASAN}

Penelitian ini adalah suatu penelitian deskriptif yang bertujuan untuk mengetahui jumlah penderita buta warna, proporsi laki-laki dan perempuan yang menderita buta warna dan jenis buta warna pada mahasiswa baru tahun ajaran 2018/2019 di Klinik Pratama Universitas Khairun. Penelitian ini dilakukan di Klinik Pratama Universitas Khairun pada tanggal 18 Juli 16 Agustus 2018.

Dari hasil penelitian, diperoleh populasi mahasiswa baru tahun ajaran 2018/2019 Universitas Khairun berjumlah 2595 orang. Namun, dari jumlah tersebut yang memenuhi kriteria inklusi dan eksklusi berjumlah 1021 orang.

Tabel 1. Distribusi responden mahasiswa baru tahun ajaran 2018/2019 di Klinik Pratama Universitas Khairun menurut jenis kelamin

\begin{tabular}{ccc}
\hline Jenis Kelamin & $\mathbf{N}$ & $\mathbf{\%}$ \\
\hline Laki-laki & 437 & 42,8 \\
Perempuan & 584 & 57,2 \\
\hline Jumlah & 1021 & 100,0 \\
\hline
\end{tabular}

Sumber: Data primer

Tabel 1 menunjukkan bahwa jumlah siswa yang menjadi sampel dalam penelitian sebanyak 1021 orang, yang terdiri dari 437 orang mahasiswa laki-laki $(42,8 \%)$ dan 584 orang mahasiswa perempuan $(57,2 \%)$.

Tabel 2. Distribusi hasil pemeriksaan buta warna mahasiswa baru tahun ajaran 2018/2019 di Klinik Pratama Universitas Khairun

\begin{tabular}{ccc}
\hline Hasil Pemeriksaan & $\mathbf{N}$ & $\mathbf{0}$ \\
\hline Buta warna & 9 & 0,8 \\
Tidak buta warna & 1012 & 99,2 \\
\hline Jumlah & 1021 & 100,0 \\
\hline
\end{tabular}

Sumber: Data primer

Tabel 2 menunjukkan bahwa pada pemeriksaan buta warna dilakukan pada 1021 mahasiswa baru tahun ajaran 2018/2019 Universitas Khairun didapatkan 9 orang $(0,8 \%)$ menderita buta warna dan 1012 orang $(99,2 \%)$ tidak menderita buta warna.

Tabel 3. Distribusi hasil pemeriksaan buta warna pada mahasiswa baru tahun ajaran 2018/2019 di Klinik Pratama Universitas Khairun menurut jenis kelamin

\begin{tabular}{|c|c|c|c|c|c|c|}
\hline \multirow{2}{*}{$\begin{array}{c}\text { Hasil } \\
\text { Pemeriksaan }\end{array}$} & \multicolumn{4}{|c|}{ Jenis kelamin } & \multirow[b]{2}{*}{ Jumlah } & \multirow[b]{2}{*}{$\%$} \\
\hline & $\begin{array}{l}\text { Laki- } \\
\text { laki }\end{array}$ & $\%$ & Perempuan & $\%$ & & \\
\hline Buta warna & 8 & 1,8 & 1 & 0,2 & 9 & 0,8 \\
\hline $\begin{array}{c}\text { Tidak buta } \\
\text { warna }\end{array}$ & 429 & 98,2 & 583 & 99,8 & 1012 & 99,2 \\
\hline Total & 437 & 100,0 & 584 & 100,0 & 1021 & 100,0 \\
\hline
\end{tabular}

Sumber: Data primer 
Tabel 3 menunjukkan bahwa dari 437 orang mahasiswa laki-laki yang mengikuti pemeriksaan buta warna, didapatkan 8 orang $(1,8 \%)$ menderita buta warna dan 429 orang $(97,8 \%)$ tidak menderita buta warna. Sedangkan dari 584 orang mahasiswa perempuan yang mengikuti pemeriksaan buta warna, didapatkan 1 orang $(0,2 \%)$ yang menderita buta warna dan 583 orang $(99,8 \%)$ tidak menderita buta warna .

Tabel 4. Distribusi jenis kelainan warna pada mahasiswa baru tahun ajaran 2018/2019 di Klinik Pratama Universitas Khairun

\begin{tabular}{ccc}
\hline Kelainan Warna & N & \% \\
\hline Buta Warna Partial & 4 & 44,4 \\
Buta Warna Total & 5 & 55,6 \\
\hline Jumlah & 9 & 100,0 \\
\hline
\end{tabular}

Sumber: Data primer

Tabel 4 menunjukkan bahwa dari 7 orang mahasiswa yang menderita buta warna, 4 orang $(44,4 \%)$ buta warna partial merah-hijau dan 5 orang buta warna total $(55,6 \%)$.

Tabel 5. Distribusi penderita buta warna menurut riwayat penyakit mata pada mahasiswa baru tahun ajaran 2018/2019 di Klinik Pratama Universitas Khairun

\begin{tabular}{lcc}
\hline \multicolumn{1}{c}{ Riwayat Keluarga } & N & \% \\
\hline Ada $(+)$ & 0 & 0 \\
Tidak ada $(-)$ & 9 & 100,0 \\
\hline \multicolumn{1}{c}{ Jumlah } & 9 & 100,0 \\
\hline
\end{tabular}

Sumber: Data primer

Tabel 5 menunjukkan bahwa dari 9 orang mahasiswa yang menderita buta warna, tidak ada mahasiswa yang mengalami riwayat penyakit mata sebelumnya $(0 \%)$ baik trauma atau penyakit mata lainnya.

Tabel 6. Distribusi penderita buta warna menurut riwayat keluarga pada mahasiswa baru tahun ajaran 2017/2018 di Klinik Pratama Universitas Khairun

\begin{tabular}{ccc}
\hline \multicolumn{1}{c}{ Riwayat Keluarga } & $\mathbf{N}$ & $\mathbf{0}$ \\
\hline Mengetahui & 0 & 0 \\
Tidak mengetahui & 9 & 100,0 \\
\hline \multicolumn{1}{c}{ Jumlah } & 9 & 100,0 \\
\hline
\end{tabular}

Sumber : Data primer

Tabel 6 menunjukkan bahwa seluruh mahasiswa yang menderita buta warna $(100,0 \%)$ menjawab tidak mengetahui adanya riwayat keluarga menderita buta warna. 


\section{KESIMPULAN}

Setelah melakukan penelitian mengenai buta warna pada Mahasiswa Baru Tahun Ajaran 2018/2019 di Klinik Pratama Universitas Khairun, maka dapat diambil kesimpulan sebagai berikut:

1. Dari 1021 orang mahasiswa baru tahun ajaran 2018/2019 di Klinik Pratama Universitas Khairun, didapatkan 9 orang $(0,8 \%)$ menderita buta warna.

2. Dari 437 orang mahasiswa laki-laki, didapatkan 8 orang $(1,8 \%)$ menderita buta warna, sedangkan dari 584 orang mahasiswa perempuan, didapatkan 1 orang $(0,2 \%)$ yang menderita buta warna.

3. Jenis buta warna yang ditemukan adalah 4 orang $(44,4 \%)$ buta warna partial merah-hijau dan 5 orang buta warna total $(55,6 \%)$. Jenis buta warna yang terbanyak diderita adalah buta warna total.

4. Tidak ada mahasiswa yang mengalami riwayat penyakit mata sebelumnya $(0 \%)$ baik trauma atau penyakit mata lainnya.

5. Dari 9 orang penderita buta warna, seluruhnya $(100,0 \%)$ menjawab tidak tahu dengan riwayat keluarganya yang menderita buta warna.

\section{UCAPAN TERIMA KASIH}

Penulis mengucapkan terima kasih kepada Universitas Khairun yang telah memberi dukungan dana melalui Hibah Penelitian Tingkat Fakultas Tahun Anggaran 2018, terhadap penelitian ini dan juga penulis mengucapkan terima kasih kepada pembantu peneliti pada saat proses pengumpulan informasi (data) di lapangan.

\section{DAFTAR PUSTAKA}

Bailey, G. 2017. Color Blindness. [Online]. [cited 2017 Juny 27]. Available from: URL http://www.allaboutvision.com

Fairchild, M.D. 2005. Color Appearance Models. Second Ed. John Wiley \& Sons, Ltd 2005 ISBN: 0-470-01216-1 (HB).

Friedman NJ, Kaiser PK, Trattler WB. Retina Disorders. 2005. In: Review of Opthalmology. Pennsylvania: Elsevier Saunders.

Ganong, W.F. 2003. Buku Ajar Kedokteran, Edisi Dua puluh. Jakarta: EGC.

Guyton, H.C., Hall, J.E. 2011. Penglihatan warna. Dalam Guyton \& Hall Buku Ajar Fisiologi Kedokteran. Edisi Duabelas. Jakarta: EGC. 2011.

Goldberg, Stephen. 2000. Ophthalmology, Made Ridiculously Simple, fisrt edition. Singapore. McGraw-Hill.

Ilyas, S. 2003. Uji Buta Warna. Dalam: Dasar Teknik Pemeriksaan dalam Ilmu Penyakit Mata. Edisi kedua. Jakarta. FKUI; 2003. Hal. 127-37 
TECHNO: Vol. 08 ( 01) Mei 2019

. 2005. Mata Tenang Penglihatan Menurun. Dalam: Penuntun Ilmu Penyakit Mata . Edisi ketiga. Jakarta. FKUI;

2008. Ilmu Penyakit Mata. Edisi kedua. Jakarta. FKUI.

Mengenal buta warna. [Online]. 2006. [cited 2017 May 27]. Available from: URL http://www.mitranetra.or.id

Spalton, David J. et.al. 2005. Atlas of Clinical Ophthalmology, third edition, Philadelphia. ElsevierMosby. 